\title{
Alternating Current Noise by ECG Finding
}

National Cancer Institute

\section{Source}

National Cancer Institute. Alternating Current Noise by ECG Finding. NCI Thesaurus. Code C114149.

An electrocardiographic recording showing power line interference with the electrocardiographic signal. The artifact amplitude modulation has the same frequency as the AC power system present (usually $50 \mathrm{~Hz}$ or $60 \mathrm{~Hz}$ ). (CDISC) 